\title{
Making progress in determining quality: positional accuracy of the new 1:25,000 scale digital cartography
}

\author{
Bárbara Cubillos a, Ángela Ortíz ${ }^{\text {a,* }}$, Germán Aguilera ${ }^{\text {b }}$, Sergio Rozas ${ }^{\text {b }}$, Claudio Reyes ${ }^{\text {b }}$, Ignacio \\ Parada $^{\mathbf{b}}$, Carlos Arriaza ${ }^{\mathbf{b}}$, Wilfredo Rubio ${ }^{\mathbf{b}}$, Patricio Gallardo ${ }^{\mathbf{b}}$, Héctor Nuñez ${ }^{\mathbf{b}}$ \\ a,Affiliation: Military Geographic Institute (IGM) - Cartographic Section; latitudsur@igm.cl \\ b Affiliation: Military Geographic Institute (IGM) - Geodesic Section; geodesico@igm.cl \\ * Corresponding author
}

\begin{abstract}
The digital cartographic coverage at 1:25,000 that the Military Geographic Institute is creating has been worked on using international standards, so that it constitutes a standardized and interoperable tool, for the various areas of activity in Chile. In this context, the ISO TC 211 standards and the TDS (Topographic Data Store) data model developed by the National Geospatial-Intelligence Agency (NGA) are being used.

Apart from using these standards, efforts have been aimed, from an early stage, at the determination of the quality of this product, starting this process with the study for a methodology to measure Positional Accuracy. The method defined conforms to the NSSDA test; for this, points measured in the terrain especially for this control are used, also the elimination of points that are out of range under the Chauvenet Criteria. Finally, the positional accuracy is declared in the metadata.
\end{abstract}

Keywords: Cartography, Quality, Positional Accuracy, NSSDA Test

\section{Introduction}

The Military Geographic Institute of Chile constitutes the official authority that represents the State in all those matters involving the geography and the mapping of Chilean territory. In this context, it has been working on the creation of a new national digital cartographic base at $1: 25,000$ scale.

This process was performed under ISO $^{1}$ standards in the various phases of production, which ensured the interoperability of the product and facilitates the incorporation of other information to complement it that comes from each user. The data model used is aligned with the LTDS (Local Topography Data Store), created by the National Geospatial-Intelligence Agency, for the purposes of topographic intelligence. This makes it possible to structure the portrayal of the terrain in a logical and homogeneous way, defining the attributes of each feature ${ }^{2}$ (object/element/accident) by means of a catalogue of features specific to the 1:25,000 scale.

The inclusion of metadata at the end of the process allows the producer, the Military Geographic Institute, to communicate and describe accurately the data set making up this new digital cartographic coverage, making it possible for the various users to assess its applicability, knowing its limitations and advantages.

Among the various tests that exist for validating the positional accuracy, one of those recommended for the creation of digital cartography is the NSSDA (National Standard for Spatial Data Accuracy) test. This provides

\footnotetext{
1 The "International Organization for Standardization".
}

values for actual measurements made in the field, based on a percentage of reliability, without indicating whether the product is accepted or rejected, as that would be the decision of the organization, institution or business in charge of the cartographic production. This indicator is one of the main differences compared with other tests that could be used for calculating positional accuracy.

The statistical management of the sample of control points used in the test, by means of the Chauvenet Criteria, makes it possible to identify errors that may arise both from the data and from the processes performed in obtaining this information. The application of this kind of criteria for filtering atypical is present in most of the tests for controlling the positional accuracy of the new digital cartography, the greater part of which is based on comparisons of the information created with a source of greater accuracy.

The source data for the extraction and capture of the cartographic information comes from digital orthoimages and digital surface models, which are worked on in the Datem Summit Evolution 7.4 and ArcGIS version 10.5.1 software tools.

\subsection{Background}

\subsubsection{Quality}

The dictionary of the Royal Spanish Academy defines quality as: "property or set of properties inherent in something that enable its value to be determined". ISO

\footnotetext{
${ }^{2}$ The geographic standards adopted by Chile define the use of the word feature as the abstraction of phenomena in the real world.
} 
9000 describes it as the "degree in which a set of inherent characteristics of an object fulfils requirements". Finally, in the field of geographic information, we could say that it is the degree in which a representation of reality fulfils its technical specifications and/or definitions, in a way such that the user has full knowledge of whether prior expectations are met and of the uses that can be made of it. In this sphere, ISO TC $211^{3}$ has studied, initially, and then defined standards for determining and measuring the quality of geographic information, such as in the ISO 19114, 19113 and 19138 standards, which, together, make it possible to apply rules or to standardize the quality aspects of geographic information.

The standard defines how to obtain results for the following characteristics in order to determine and declare the quality of the geographic information:

- Completeness (omission/commission)
- Logical Consistency (staying aligned to the data
model)
- Positional Accuracy (positional component)
- Temporal accuracy
- Thematic accuracy

In the context of the work considered here, the tasks performed to determine specifically the positional accuracy of the cartography at 1:25,000 scale are demonstrated as follows.

\subsubsection{Positional accuracy}

Among the various tests that there are for validating positional accuracy, one of those recommended for the creation of digital cartography is the NSSDA test. This gives values for real measurements made over the terrain as a function of a percentage of confidence or reliability, without indicating whether the product is accepted or rejected, as that will be the decision of the entity, institution or business in charge of the cartographic production, or, finally, of the user. This indicator is one of the main differences in relation to other tests that can be used in calculating positional accuracy.

The main configuration settings to be applied include determining the geographic extent within which the test is to be performed, a specific level of confidence for the error of the sample, which is generally between 90 and $95 \%$, and a minimum of 20 control points that need to be included and distributed in the study area in order to be analyzed using statistics.

Given that the work of creating this digital cartography runs from north to south in Chile and is put into effect by Phases, the determination of positional accuracy is completed as follows:

- A minimum of 20 final points in the area are processed

- It is determined up to a $90 \%$ level of confidence

3 Technical Committee of the ISO that studies and defines Standards for Geographic Information.

${ }^{4}$ CHAUVENET, Williams. Manual of Spherical and Practical Astronomy Vol II. GREENWALT, Clyde and SHULTZ,
The work done here corresponds to Phase 1, covering the Arica and Parinacota, Tarapacá and Antofagasta Regions. Additionally and optionally, before the statistical treatment of a sample, it is recommendable to carry out a check on the set of coordinates to compare, applying a method for detecting and recording atypical observations, such as for example the Rejection Criteria of Chauvenet ${ }^{4}$. This criteria makes it possible to determine whether a piece of experimental data from a sample set has the probability of being atypical and considered as the result of bad processing or procedures during its capture. In this way, applying the Chauvenet Criteria functions as a filter prior to the statistical analysis of the data sample, ensuring the removal of those data records that show up as erroneous.

\section{Methodology}

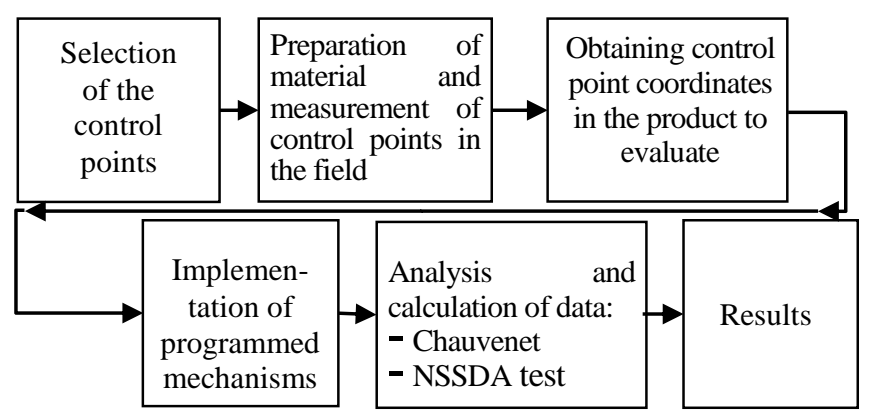

Figure 1. Work flow for obtaining positional accuracy. Source: IGM.

\subsection{Selection of Control Points}

By means of a comprehensive series of checks, the points that should enter into the statistical analysis of the sample for validating the positional accuracy of the vectors are established. These points will be those which best fulfill the criteria established for applying the test:

- Homogeneous distribution in the area defined (Phase I), which is divided into four quadrants, where there should be a minimum of $20 \%$ of control points and their respective diagonals.

- Separation equivalent to the tenth part of the hypotenuse of the rectangle covering the study zone.

- Mínimum of 20 points in the area being controlled.

Moreover, it is suggested that, for cartography of vectorial origin, the control points be located at the intersection of highways, roads, rivers, channels, paths or fences, among others. These points should be easily visible in the images, besides being part of one of the features captured during the process of map creation.

Melvin. Principles of error theory and cartographic applications. Missouri (EE.UU), 1962. 

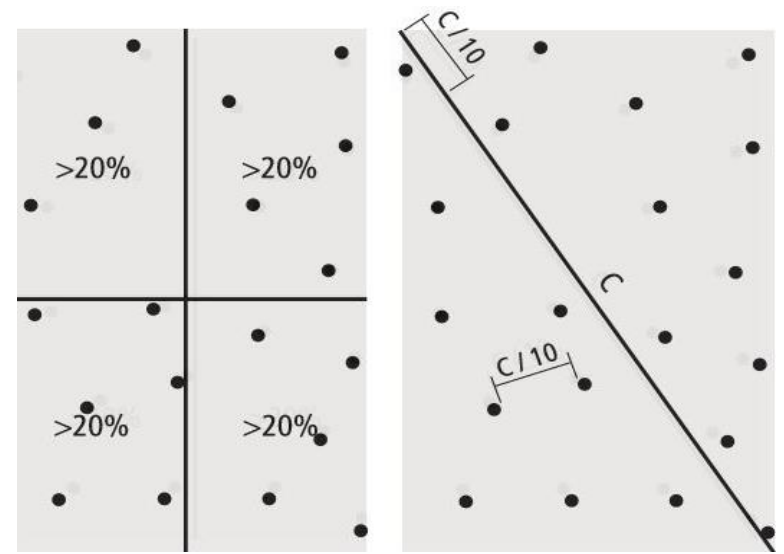

Figure 2 (left): Ideal test point distribution. Figure 3 (right): Ideal test point spacing. Source: Positional Accuracy Handbook

\subsection{Field points}

The positional accuracy of a cartographic product is calculated comparing the information extracted from it with a source of greater accuracy. The points used for this comparison should be well defined, be easy to find and to measure in both sources; the cartographic product under assessment and the source of greater accuracy.

In this case, the points corresponding to a source of greater accuracy were measured in the field with GNSS receivers over a period of at least 2 hours, obtaining centimetric precision. These technical specifications for measurement follow the rules indicated in the "Highways Manaul" as shown in the following table:

TABLA 2.302.2.A

TIEMPOS DE MEDICIÓN GNSS DE ACUERDO CON LA FRECUENCIA

\begin{tabular}{|c|c|c|}
\hline Rango Distancia (km) & L1 & L1/L2 \\
\hline $0-2$ & $20 \mathrm{~min}$ & $20 \mathrm{~min}$ \\
\hline $2-10$ & $30 \mathrm{~min}$ & $30 \mathrm{~min}$ \\
\hline $10-30$ & $1 \mathrm{~h}$ & $40 \mathrm{~min}$ \\
\hline $30-70$ & - & $1 \mathrm{~h}$ \\
\hline $70-150$ & - & $1,5 \mathrm{~h}$ \\
\hline$>150$ & - & $2 \mathrm{~h}$ \\
\hline
\end{tabular}

The result of this work is the coordinates of each point and a monograph that identifies the point measured clearly and in detail.

Among the features compared in this study it is possible to find football pitches, intersections of fences, water tanks, among other features.

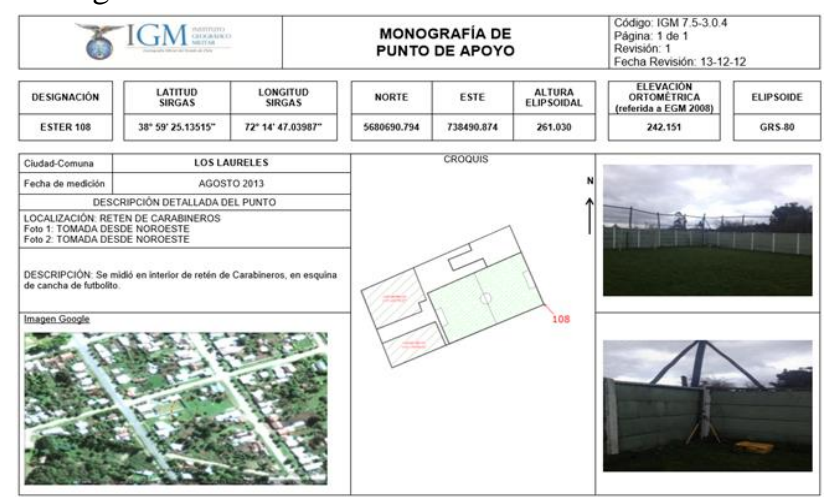

Figure 4: Example of a monograph for the control points. Source: IGM.

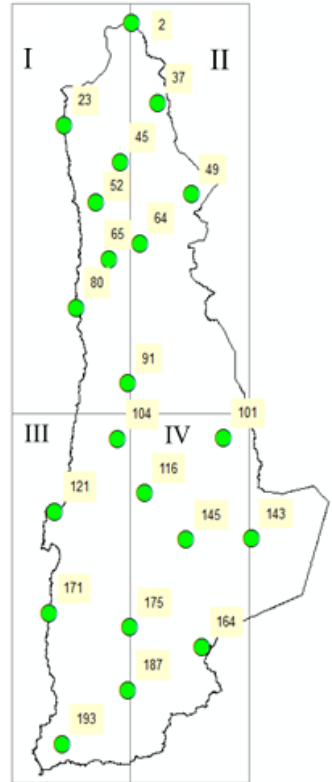

Figure 5: Distribution of Phase I control points. Source: IGM.

\subsection{Obtaining coordinates of the control points in the cartography}

The procedure performed at this stage corresponds to the extraction of coordinates, point by point, from the software used for creating the cartography, selecting the element where the node corresponding to the control point is located. During this stage it is recommended that this information be validated with the field monograph.

In the image shown as follows one can see the fence element node and the $\mathrm{N}^{\circ} 8$ control point, which should be identical as points. This information was corroborated with the monograph that indicates that the measurement was made at the intersection of fences, stating that both measurements, in the field and in the image, relate to the same point.

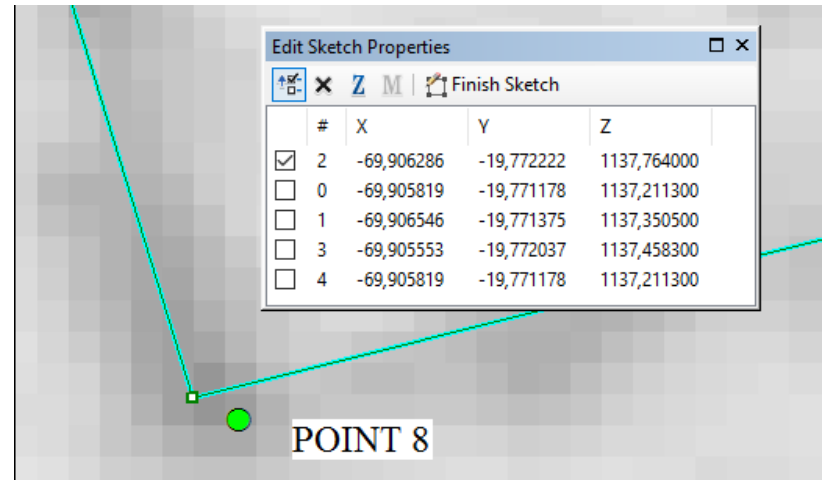

Figure 6: Node of the element and control point. Source: IGM. 


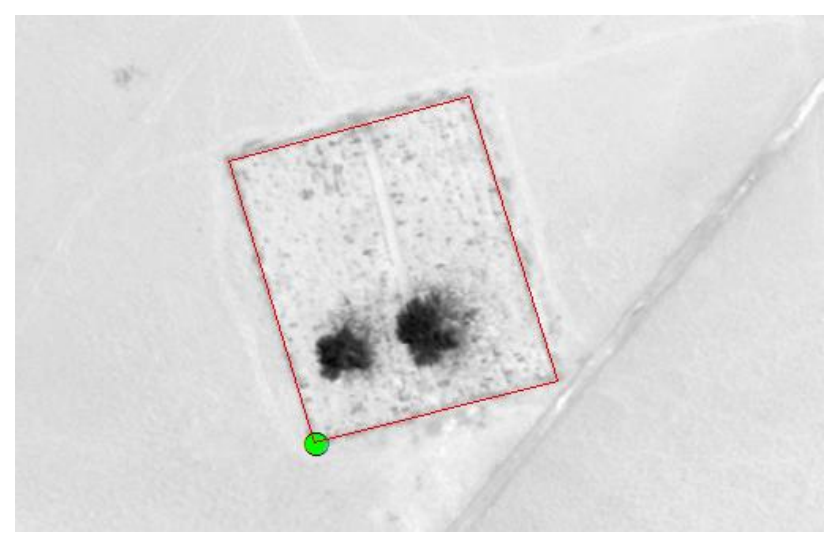

Figure 7: Feature and control point. Source: IGM

\subsection{Setting up of programmed mechanisms}

For a more efficient management of the information and of the simplification of the calculations, the geographic coordinates obtained from the cartography were transformed into UTM coordinates with the CoticchiaSurace $^{5}$ formulas for the conversion of coordinates.

Also, a mechanism was configured for the analysis and comparison of the coordinates for the control points, where the X and Y components need to be UTM coordinates and the heights should be orthometric. Within this aspect, it is possible to see the results from the observations typified and used in the Chauvenet Criteria.

This tool works as a filter, prior to the comparative analysis of the positional accuracy, ensuring the removal of observations that show up errors, and giving as a result a robust sample for analyzing the information.

\subsection{Processing the sample set}

\subsubsection{Calculation of the root mean square error (RMSE)}

In order to do this calculation, the coordinates of the control points obtained in the field should be entered into the spreadsheet of the NSSDA test; so should the coordinates extracted from the cartography. By means of the associated formulas, the root mean square error (RMSE) is obtained, also the accuracy to declare.

Step 1: Enter the name of the point and the coordinates obtained in the field, being the source of greater accuracy (Absolute Data item)

Step 2: Enter the coordinates obtained from the vectors of the cartography

\begin{tabular}{|c|r|r|r|r|r|r|r|}
\hline $\mathbf{N}^{\circ}$ PC & \multicolumn{3}{|c|}{ Step 1 } & \multicolumn{3}{c|}{} & \multicolumn{2}{|c|}{ Step 2 } \\
\hline & Name & $\mathbf{X}$ & $\mathbf{Y}$ & $\mathbf{Z}$ & $\mathbf{X}^{\prime}$ & $\mathbf{Y}^{\prime}$ & $\mathbf{Z}^{\prime}$ \\
\hline $\mathbf{1}$ & & & & & & & \\
\hline $\mathbf{2}$ & & & & & & & \\
\hline
\end{tabular}

Figure 8. Extract from the table of the programmable NSSDA Test mechanism

5 COTICCHIA, Alberto - SURACE, Luciano. Equations Coticcia- Surace.
After this, it will be possible to see in the calculation spreadsheet the differences present in the values of the $(\mathrm{x}),(\mathrm{y})$ and $(\mathrm{z})$ coordinates, together with the results of the positional accuracy for the variables both individually and combined together.

In the following table one can see the factors that were applied to the RMSE for a percentage of confidence at $90 \%$. From this, the linear values should be used when one works only with a single component or circular values when working with two components.

\begin{tabular}{|c|c|c|}
\hline & Probabilidad & Factor \\
\hline \multirow[t]{6}{*}{ Sumary of Linear Precision Indexes } & 0,5000 & $0,6745 \sigma \mathrm{x}$ \\
\hline & 0,5751 & $0,7979 \sigma \mathrm{x}$ \\
\hline & 0.6827 & $1.0000 \sigma \mathrm{x}$ \\
\hline & 0,9000 & $1,6449 \sigma \mathrm{x}$ \\
\hline & 0,9500 & $1,9600 \sigma \mathrm{x}$ \\
\hline & 0,9973 & $3,0000 \sigma \mathrm{x}$ \\
\hline \multirow{6}{*}{ Sumary of Circular Precision Indexes } & 0,3935 & $1,0000 \sigma \mathrm{c}$ \\
\hline & 0,5000 & $1,1774 \sigma c$ \\
\hline & 0.6321 & $14142 \pi c$ \\
\hline & 0,9000 & $2,1460 \sigma \mathrm{c}$ \\
\hline & 0,9500 & $2,4477 \quad \sigma \mathrm{c}$ \\
\hline & 0,9978 & $3,5000 \sigma c$ \\
\hline
\end{tabular}

Figure 9: Summary of Formulas and Conversion Factors. En: Principles of Error Theory and Cartographic Applications. $2^{\circ}$ ed. EEUU, Aeronautical Chart and Information Center. pp 67.

\subsection{Results}

34 control points were studied, distributed over four quadrants - I, II, III and IV - with identical dimensions.

Out of the whole set of data, 30 control points fcomply with the criteria for homogeneity and distance that the test requires, while 4 were discarded due to being atypical values.

The analysisof the set of 30 elements yielded the following results:

\begin{tabular}{|c|c|c|c|}
\hline \multirow{6}{*}{ Linear } & \multirow{2}{*}{$\mathbf{X}$} & RMSE & 1.333 \\
\hline & & NSSDA $90 \%$ & 2.016 \\
\hline & \multirow{2}{*}{$\mathbf{Y}$} & RMSE & 1.248 \\
\hline & & NSSDA $90 \%$ & 4.389 \\
\hline & \multirow{2}{*}{$\mathbf{Z}$} & RMSE & 1.441 \\
\hline & & NSSDA $90 \%$ & 2.883 \\
\hline \multirow{2}{*}{ Circular } & \multirow{2}{*}{$X Y$} & RMSEr & 1.826 \\
\hline & & NSSDA $90 \%$ & 5.478 \\
\hline
\end{tabular}

Figure 10. Table of results. Source: IGM.

Format for expressing the test:

- $\quad$ Verified for 5,478 meters of horizontal accuracy at a $90 \%$ level of confidence

- $\quad$ Verified for 2,883 meters of vertical accuracy at a $90 \%$ level of confidence 


\section{Conclusion}

The results of the test may vary in accordance with how dense the quantity of control points is, taking into consideration the fact that a sample with a larger quantity of elements will always be more representative.

The inclusion of criteria for filtering the statistical sample makes it possible to perform a more solid analysis of the dataset, which moreover it is possible to use for discovering anomalies within the zones where a large quantity of outlier values are present. This procedure is not obligatory within the application of the NSSDA test, nevertheless, the use of a statistical criteria ensures conclusively the quality of the sample to work on.

The percentage of confidence that is shown in the results, according to the format proposed for expressing the test, in this case, at $90 \%$, indicates that if one performs " $n$ " quantity of tests at any point of the geographic zone studied, only $10 \%$ of the set of " $n$ " samples would be outside the accuracy demonstrated by the test.

The factor used in the calculation of the percentage of confidence was chosen in accordance with the size of the sample and matches the Map Accuracy Standard as an indicator, equivalent to a $90 \%$ confidence level. The use of a higher indicator, $95 \%$ for example according to the terminology suggested for the test, makes it necessary to include a greater number of control points within the sample; these would need to reach up to between 95 and 100 elements, according to recommendations in the bibliography ${ }^{6}$.

\section{References}

Angostos, Miguel A. (2012) "Desarrollo y análisis de un procedimiento operatorio para la medición de piezas circulares mediante proyector de perfiles" (Development and analysis of an operating procedure for measuring circular pieces by means of a profile projector). Cartagena, España. 22 p.

Atkinson, Alan D. (2005) "Control de Calidad Posicional en Cartografía: Análisis de los Principales Estándares y Propuesta de Mejora" (Positional quality control in mapping: analysis of the main standards and a proposal for improvement). Jaén, España.

Chauvenet, Williams. (1962) Manual of Spherical and Practical Astronomy Vol II. GREENWALT, Clyde and SHULTZ, Melvin. Principles of error theory and cartographic applications. Missouri, EE.UU.

Coticcia, Alberto \& Surace, Alberto. (1975) Ecuaciones (equations) Coticchia-Surace. "Bolletino di Geodesia e Science Affini”, Num. 1. Florence, Italy.
Fernandez, Felipe \& Gonzalez, Daniel. (2014) "Aplicación de distintos test de exactitud posicional a una nube de puntos obtenida desde un sensor LIDAR" (Application of varying positional accuracy tests to a point cloud obtained from a LIDAR sensor). Santiago, Chile.

FGDC. Geospatial Positioning Accuracy Standards. (2002) PART 3: National Standard for Spatial Data Accuracy, FGDC-STD-007.3-1998. Virginia, EE.UU.

Minnesota Governor's Council on Geographic Information. (1999) Positional Accuracy Handbook. Minnesota, EE.UU.

"Ministerio de Obras Públicas" (Chilean Public Works Ministry) . (2020) "Manual de Carreteras Volumen $\mathrm{N}^{\circ} 2$ Procedimientos de Estudios Viales" (highways manual, vol. 2, procedures for road and highways studies). Santiago, Chile.

\footnotetext{
6 ATKInSON, Alan D. "Control de Calidad Posicional en Cartografía: Análisis de los Principales Estándares y Propuesta de Mejora”. Jaén, 2005.
} 